\title{
Analysing the Energy Efficiency Renovation Rates in the Dutch Residential Sector
}

\author{
Shima Ebrahimigharehbaghi ${ }^{1}$, Faidra Filippidou ${ }^{1,2}$, Paula van den Brom ${ }^{l}$, Queena k. Qian ${ }^{l}$, Henk J. Visscher ${ }^{1}$ \\ ${ }^{1}$ Delft University of Technology, Faculty of Architecture and the Built Environment, OTB, Julianalaan134, 2628 \\ $B L$, Delft, The Netherlands \\ ${ }^{2}$ Currently at European Commission, DG Joint Research Centre Energy, Transport and Climate Directorate
}

\begin{abstract}
The housing stock has a major share in energy consumption and $\mathrm{CO}_{2}$ emissions in the Netherlands. $\mathrm{CO}_{2}$ emissions increased 2.5\% year-on-year in the first quarter of 2018. Higher $\mathrm{CO}_{2}$ emissions were principally due to raised gas consumption for heating in the residential and service sector ${ }^{1}$. Energy efficiency renovations can contribute considerably in reducing energy consumption and achieving the EU and national energy efficiency targets. However, based on recent research ${ }^{2}$, the renovation rates in the Dutch social housing sector are not adequate to achieve the energy efficiency targets. Moreover, the deep renovation rates are almost negligible in this sector. The Dutch housing stock consists of the owner-occupied sector and rental sector (social housing and private rental houses) with shares equal to $69.4 \%$ and $30.6 \%$, respectively. Considering the major share of the housing sector in energy consumption, the aim of the current study is to evaluate and compare the renovation rates in these sectors and the potential contribution of each one in achieving the energy efficiency targets. By renovation rate, we mean the percentage changes in the number of the identical houses moving from one energy label to the more efficient energy labels. The Netherlands Enterprise Agency (RVO) and Statistics Netherlands (CBS) databases are used to conduct the statistical analysis. The results show that the renovation rates are almost the same in these three sectors, despite the expectation of much higher renovation rates in the social housing sector.
\end{abstract}

\section{Introduction}

Worldwide buildings consume $30 \%$ of the final energy and more than $55 \%$ of global electricity demand ${ }^{3}$. The existing residential sector is the single most important player, worldwide - but also in the European Union (EU) and the Netherlands - since existing dwellings are responsible for $25.7 \%$ if the final energy consumption in the EU 28 (all 28 Member States) ${ }^{4}$. On top of that, the energy intensity of existing dwellings is increasing. Due to the long lifespan of buildings, existing buildings today will constitute a major part of the future housing stock for several decades ${ }^{5}$. Energy renovations offer unique opportunities for reducing the energy consumption and greenhouse gas (GHG) emissions on a national scale in the Netherlands, but also on an EU and global level. Energy renovation rates assumed by policy makers or are quoted as "needed renovation rates" usually range from $2.5-3 \%{ }^{6-10}$. However, at current rates it is claimed that more than 100 years will be needed to renovate the EU building stock ${ }^{11}$. The current renovation rate is $1-2 \%$ annually $5,12,13$. In the Netherlands, it is expected that the renovation activity will be greater than the construction and demolition activity in the future ${ }^{5,12}$.

The mix of tenure of dwellings is an important factor for the ability to renovate regarding both the energy savings and the impact on the rate of energy renovations 14,15 . The total amount of dwellings in the Netherlands is 7.5 million. In 2017, The owner-occupied sector amounts to $69.4 \%$ of the total, whereas the rental sector comprises $30.6 \%$ of the total 16. The vast majority of dwellings belong to the owneroccupied sector. This presents a great opportunity for policy implementation targeting energy renovations of dwellings. In this paper, we focus on the comparison of the renovation rates in the Dutch owner-occupied and rental sector. Fig 1 presents the evolution of the registered energy labels of the total housing stock in the Netherlands. However, out of the $2,042,714$ dwellings having a registered energy label, the $1,839,719$ belong to the non-profit housing sector ${ }^{17}$.

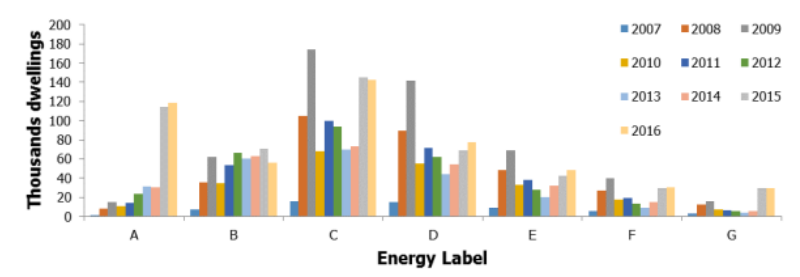

Fig 1. Evolution of the energy label distribution of the Dutch housing stock from 2007 to 2016 (source: PBL 2017)

Two major directives are currently in force, on an EU level, to tackle the issue of energy efficiency improvement of buildings - the Energy Efficiency Directive (EED) and the Energy Performance Buildings Directive $(\mathrm{EPBD})^{18,19}$. Improving the efficiency of the building stock is a central pillar for the carbon reduction goals of the Member States (MS) and the EU as a whole. For this reason, in June 2018, in order to better identify the need and urgency of a decarbonised future energy system, the European Commission, amended both the EPBD and the EED to connect them under the Directive (EU) 2018/844 and the 'Clean Energy for All Europeans' package ${ }^{20}$. In this directive the energy renovation of the existing housing stock, with an

\footnotetext{
*Corresponding author: $\underline{\text { S.Ebrahimigharehbaghi@tudelft.nl }}$
} 
emphasis on the cost effectiveness and the long-term renovation strategies of the MSs, plays a major role towards achieving the set goals (Member States).

The Netherlands, as every MS, is translating the directives into national legislation and incentives. Historically, policy measures have been in place since the last quarter of the $20^{\text {th }}$ century, mainly through building decrees. The energy consumption of buildings has been regulated since 1975 consisting of limits on transmission losses based on insulation values ${ }^{21}$. In 1995 these limits were expanded to include the national Energy Performance Standard (Energy Performance Coefficient for new buildings/ Energy Performance Certificate for existing buildings (EPC)) which is a nondimensional figure that expresses the energy performance of a building depending on the energy consumed for space heating, hot water, lighting, ventilation, humidification and cooling $^{12}$. In addition, in 2008, the EPBD is applied, setting the sets of goals for the built environment high. New buildings and major renovations in the Netherlands are required to meet specific standards e.g. RC-values of floors, facades, roofs and U-values of windows, as of January 2015. The majority of policy measures focus on the energy efficiency of buildings and the energy neutrality of new buildings. However, the realization of energy efficient measures or energy renovations of the dwellings could go even further.

Considering the major share of the housing stock in the final energy consumption, the aim of the current paper is to evaluate the energy renovation rate in the owner-occupied and rental sectors and the potential contribution of different energy renovation levels in achieving the energy efficiency targets. To do so, we use the percentage changes in the number of the identical houses moving from one energy label to a more energy efficient label to measure the renovation rate. We used the energy label database provided by the Netherlands Enterprise Agency (RVO). We integrated the RVO database with the data from Netherlands Statistical Bureau (CBS). The CBS data is necessary to categorise the RVO energy label based on different sectors, owneroccupied, rental, etc., in the Dutch dwelling stock.

This paper is structured as follows. The second section sets the background and presents an overview of the data and methods of our research. The third section introduces the results. The fourth section deals with our experiences concerning the evaluation of renovation rates in the owneroccupied sector and the longitudinal data analysis. Finally, the fifth section elaborates on policy implications and draws conclusions.

\section{Methodology}

The database and method of analysis are described in the following subsections. In subsection 2.1, the energy label from RVO and CBS are presented. In subsection 2.2, the method of analysis is illustrated.

\subsection{Database}

\subsubsection{RVO}

The first database that is used for this research is the Energy label database of RVO. This database contains every registered energy label for the years 2003-2017 of all buildings in the Netherlands. For this research, only the residential buildings are considered. Since January 2008 it is mandatory to have an energy label for every house that will be rented out or will be sold in the Netherlands, according to the European Commission (EC) regulation.

If the dwelling is renovated the owner has an incentive to update the energy label because a "better" energy label can increase the rental price and has a positive influence on the selling price. Consequently, some buildings have more than one registered energy label. This makes it possible for us to track the renovation rate of the housing stock. However, one should realize that many buildings, and therefore also renovations, are not registered because dwellings that are not sold or rented out are not obliged to register their energy label.

\subsubsection{Dutch statistics data}

The aim of this paper is to compare the renovation rate of different sectors (owner-occupied, private rent and social rent). The original Energy label database doesn't contain information about which sector the dwellings belong to. Therefore, the database is linked to a database from Statistics Netherlands that contains information about which sector the dwelling belongs on an address level. The database distinguishes three different sectors: owner-occupied, subsidised rental, and unsubsidised rental sector. Table 1 shows the number of houses per each sector for the years 2008-2017.

Table 1. Number of houses included in the analysis for each sector

\begin{tabular}{llllllllll}
\hline & $2008-9$ & $2009-10$ & $2010-11$ & $2011-12$ & $2012-13$ & $2013-14$ & $2014-15$ & $2015-16$ & $2016-17$ \\
\hline Owner-occupied & 55735 & 96748 & 121430 & 137239 & 148473 & 155228 & 160315 & 229705 & 283511 \\
Social housing & 107361 & 198059 & 213457 & 249274 & 271449 & 285944 & 298361 & 315234 & 330814 \\
Private rental sector & 121081 & 226807 & 254641 & 291150 & 320251 & 340240 & 356730 & 391504 & 427478 \\
Total dwellings & 284177 & 521614 & 589528 & 677663 & 740173 & 781412 & 815406 & 936443 & 1041803 \\
\hline
\end{tabular}

\subsection{Method of Analysis}

Up to now, the energy label database is mainly used to track the evolution of the energy label distribution of the Dutch housing stock (see figure 1), with the main aim to track the energy efficiency state of the housing stock per year. This paper however aims to track the renovation rate of the housing stock per year. Additionally, we compare the renovation rate per housing sector.

For this reason, we only included houses that have at least a registration for the energy in the year 2008. This makes it possible for us to "track" the same houses over the years. This makes the number of cases in the database drop significantly (from $1,041,803$ to 284,177 ), still we believe the data is a representative sample for identifying the renovation rate per sector. The reason behind this assumption is that the incentive for registering an energy label for a house is more or less the same per sector. In the rental sector, an energy label has to be registered when the house is rented out. In the owneroccupied sector, an energy label has to be registered when the 
house is sold. In both cases the incentive to update the label if renovation measures were carried out is present because it can influence the rental price and the selling price.

However, it is expected that the number of houses registered for the rental sector will be significantly higher than for the owner-occupied sector for two reasons: firstly, because it is expected that tenants move more frequently than homeowners, and secondly because the social housing sector was forced to register more houses due to a signed covenant that dictates housing associations to renovate their dwelling stock to an average energy label B by 2020 .

To analyse the data descriptive statistics are used. In the first step of the analysis, the change in energy label per year is studied for the total database. In the second step, similar analyses are done on a split file to compare the results for different housing sectors (owner-occupied, subsidized rental and unsubsidized rental houses). When the change of energy label per year and per sector is known the magnitude of the renovations are studied in more detail in the third step, by presenting the percentages of "label-steps" per renovation per year (differing from 1 label step to 5 label steps). In the fourth step, the "label-steps" are studied more in depth. For example, for the houses that underwent a renovation increasing one label step, we show if the renovation was executed from a $\mathrm{G}$ to an $\mathrm{F}$ label or from a $\mathrm{B}$ to an $\mathrm{A}$ label and so forth. We apply the same method to dwellings that underwent two, three, four or five label steps. This is first done for the owner-occupied sector, then for the social housing sector and finally also for the private rental sector.

\section{Results}

\subsection{Number of houses per energy label per year for each sector}

The analysis of the total housing sector shows that 269,456 houses have a registered energy label since the year 2008. 101,725 of those houses have a better energy label in 2017 compared to 2008. As expected the results show that significantly more rental dwellings have an energy label than owner-occupied houses (owner-occupied: 53,114; subsidised rental: 101,771 houses; unsubsidised rental: 114,571). The percentage of renovations, however, do not differ much: owner-occupied 33\%, subsidised rental $39.7 \%$, unsubsidised $38.3 \%$ (Fig 2, Fig 3, Fig 4).

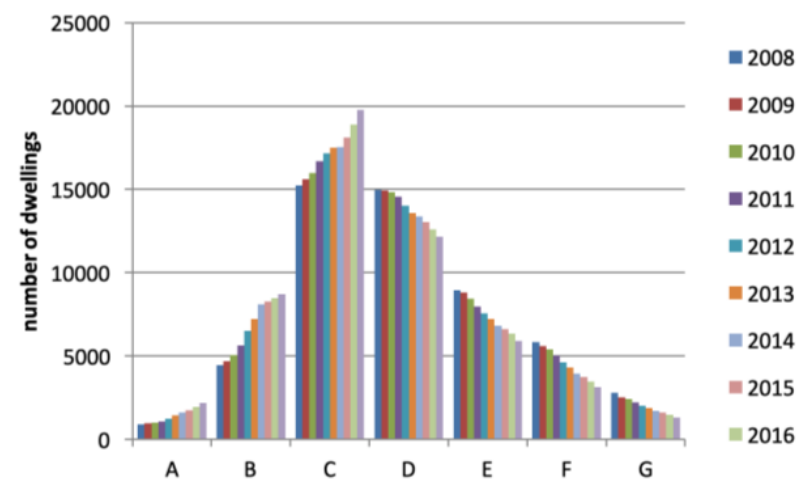

Fig 2. Number of houses per energy label per year for the owneroccupied sector based on sample $2008(\mathrm{n}=55735)$

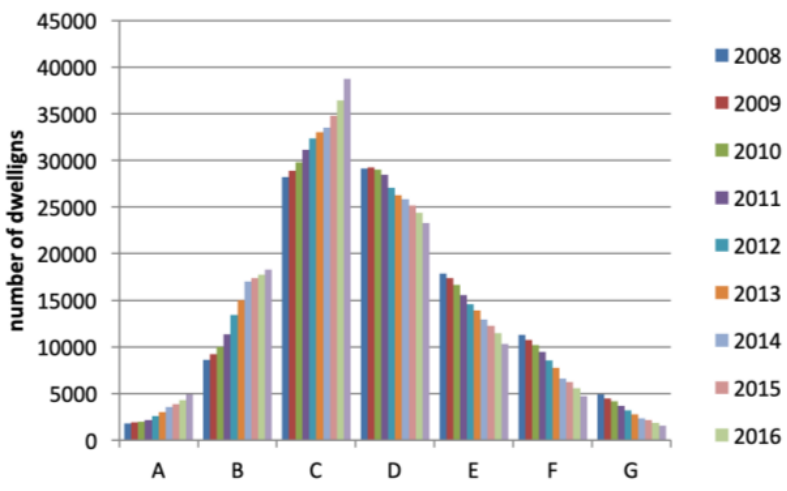

Fig 3. Number of houses per energy label per year for the subsidised rental sector based on sample $2008(\mathrm{n}=107361)$

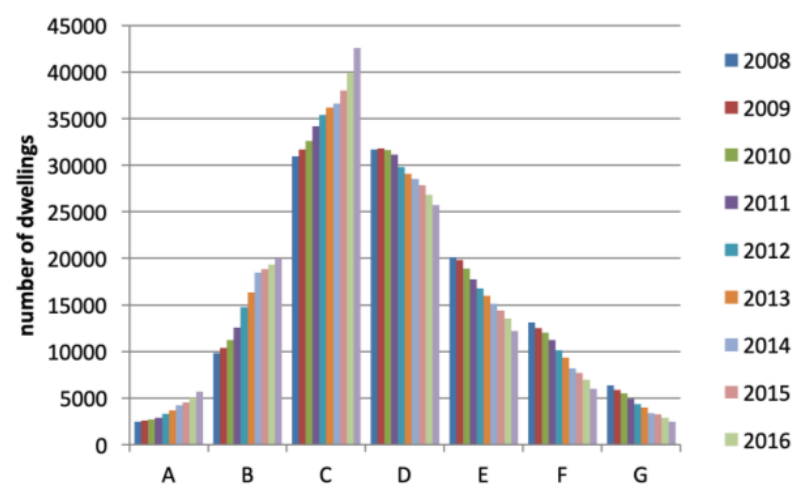

Fig 4. number of houses per energy label per year for the unsubsidized rental sector based on sample $2008(n=121081)$

\subsection{Comparison of Renovation Rates (RRs)}

Five types of renovation rates have been calculated for different sectors during 2008 and 2017; one label step (RR1), two label steps (RR2), three label steps (RR3), four label steps (RR4), and five label steps (RR5). The rates have been calculated as the percentages of dwellings that the energy labels have been changed of the total number of dwellings per sector. For instance, RR1 in 2008-9 shows the percentage of houses that the energy label is improved one step forward in 2009 compared to 2008 . 
Table 2. Different types of renovation rates

\begin{tabular}{cccccc}
\hline $\begin{array}{c}\text { Original } \\
\text { Label }\end{array}$ & $\begin{array}{c}\text { 1-Label } \\
\text { step }\end{array}$ & $\begin{array}{c}\text { 2-Label } \\
\text { steps }\end{array}$ & $\begin{array}{c}\text { 3-Label } \\
\text { steps }\end{array}$ & $\begin{array}{c}\text { 4-Label } \\
\text { steps }\end{array}$ & $\begin{array}{c}\text { 5-Label } \\
\text { steps }\end{array}$ \\
\hline A & - & - & - & - & - \\
B & A & - & - & - & - \\
C & B & A & - & - & - \\
D & C & B & A & - & - \\
E & D & C & B & A & - \\
F & E & D & C & B & A \\
G & F & E & D & C & B \\
\hline
\end{tabular}

Fig 5 shows different types of renovation rates in the owner-occupied sector. The RR1\&2 have the highest percentages. As shown, different types of renovations follow the same patterns in increasing and decreasing. In 2010 and 2011 , the percentage of RR 1 was almost equal to $3 \%$. It might be due to the effects of implementing policies, such as "Energy label and certificate for houses" and "More with Less" starting in 2008.

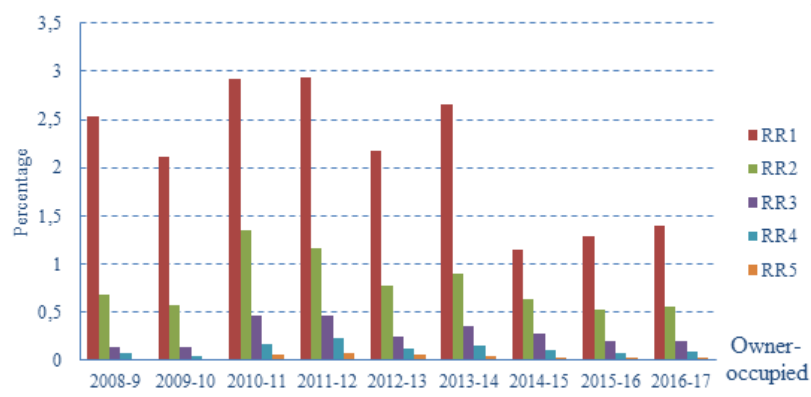

Fig 5. Different renovation rates in the owner-occupied sector

For the rental sectors, the RR1\&2 also have the highest percentages compared to other types of renovation rates. The highest percentage of RR1 for social and private rented houses are equal to $3.6 \%$ and $3.5 \%$, respectively. The change in the calculation of energy labels in $2014^{1}$, has influenced the pattern of renovation rates and the comparison is impossible with the previous years (Fig 6 and Fig 7).

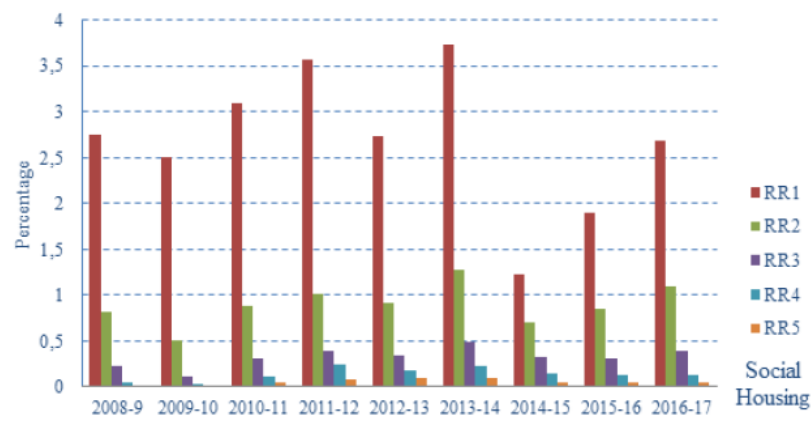

Fig 6. Different renovation rates in the social housing sector

\footnotetext{
${ }^{1}$ The method for the calculation of EI-Energy label (ISSO 2009) is changed. A new method of "Nader Voorschrift" (Further prescription) is proposed. The new method is connected to the Woningwaarderingsstelsel (WWS, Housing evaluation system), and it aimed to be more detailed and updated than the EI-Energy label method ${ }^{12}$.
}

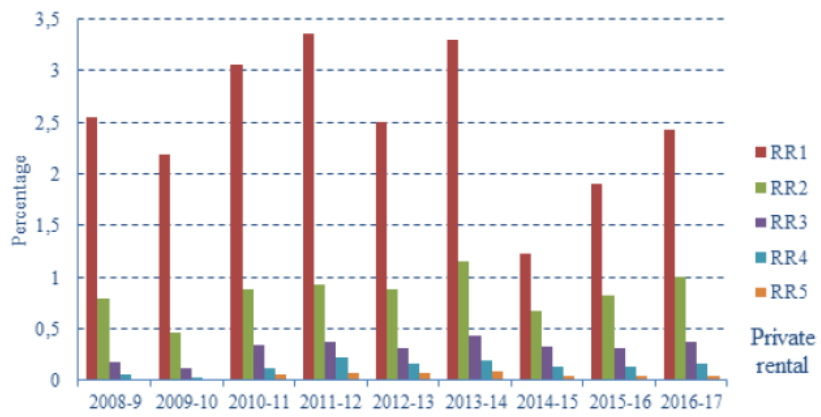

Fig 7. Different renovation rates in the private rental sector

\subsection{Lower Types of Renovation Rates}

In this section, we have shown the specific energy label change for each type of renovation rate, e.g. for RR1 from $A$ to $\mathrm{B}^{2}$ ' In the figures and tables, ' $\mathrm{O}$ ', ' $\mathrm{S}$ ', and ' $\mathrm{P}$ ' are the owner-occupied, social, and private rental sectors.

\subsubsection{1- Step energy label renovation (RR1)}

Fig 8 presents the RR1 in the owner-occupied sector. The highest percentage of energy label is from label $\mathrm{D}$ to $\mathrm{C}$. The $\mathrm{C}$ to $\mathrm{B}$ has the second highest percentages for the years (20102014). The highest percentage of RR1 is from (D to C) and equal to $1.2 \%$. Again, the difference in the chart pattern after and before 2014 is explicit.

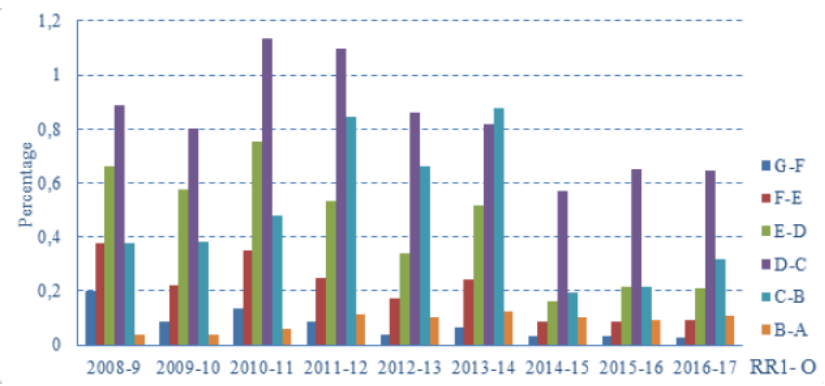

Fig 8. Renovation rate (1-step) in the owner-occupied sector

Similar to the owner-occupied sector, for the rental sectors, the percentages are not so high (social housing: up to $1.38 \%$, private rental sector= up to $1.21 \%$ ). Again, the 1-step energy label from ( $\mathrm{D}$ to $\mathrm{C}$ ) has the highest percentage equal to $1.38 \%$ and $1.21 \%$ for the social housing and private rental sectors, respectively. For the years 2011-2013, the (C to B) is in the second rank. Finally, the change in the calculation methods of energy labels make the comparison impossible for the years before and after 2014. For these years, the D to C has considerably large percentages compared to other 1-step energy labels (Fig 9 and Fig 10).

\footnotetext{
${ }^{2}$ The figures only are shown for the 1 and 5 steps energy labels since it needs too much spaces.
} 


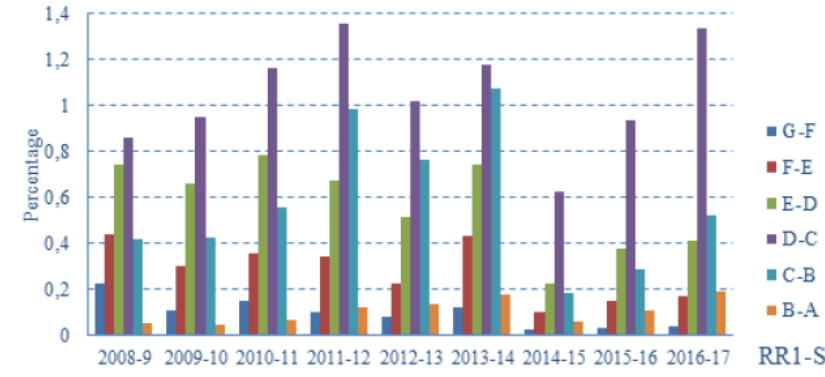

Fig 9. Renovation rates (1-step) in the social housing

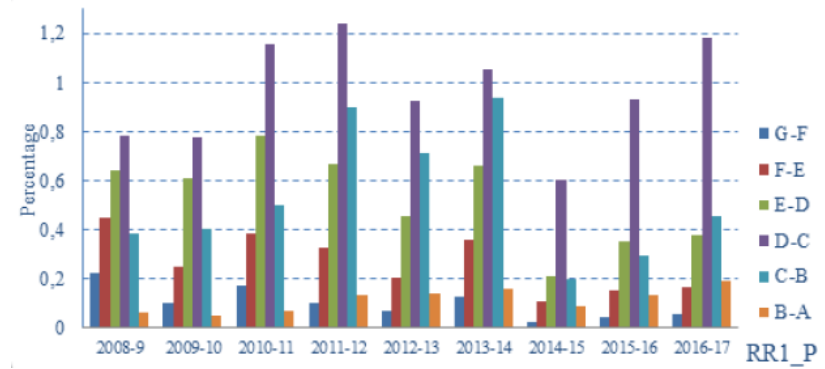

Fig 10. Renovation rates (1-step) in the private rental sector

\subsubsection{2- Steps energy label renovation (RR2)}

In general, the percentages are very low with a range $(0.01$ $0.49 \%$ ) and less than RR1. Again, the highest percentages of $\mathrm{RR} 2$ are from (E to $\mathrm{C}$ ) and equal to $0.49 \%$ for the private rental sector. In 2013, the percentages of 2-steps energy labels are higher for (D to B) compared to the (E to C) for all of the sectors. For the owner-occupied sector and for 2010-2014, the second rank is for (D to $\mathrm{B}$ ). For the rental sector, we cannot make this conclusion, since the (F to $\mathrm{D})$ sometimes has higher percentages (Table 3 ).

Table 3. Two-Steps energy labels in different sectors

\begin{tabular}{l|lllll|lllll|lllll}
\hline \multicolumn{10}{c}{ RR2-O } & \multicolumn{10}{c}{ RR2-S } \\
\hline Labels & G-E & F-D & E-C & D-B & C-A & G-E & F-D & E-C & D-B & C-A & G-E & F-D & E-C & D-B & C-A \\
$2008-9$ & 0,17 & 0,24 & 0,17 & 0,09 & & 0,17 & 0,30 & 0,22 & 0,11 & 0,01 & 0,19 & 0,26 & 0,22 & 0,10 & 0,02 \\
$2009-10$ & 0,06 & 0,17 & 0,20 & 0,12 & 0,01 & 0,06 & 0,16 & 0,17 & 0,09 & 0,01 & 0,05 & 0,16 & 0,16 & 0,09 & 0,01 \\
$2010-11$ & 0,14 & 0,38 & 0,56 & 0,25 & 0,03 & 0,09 & 0,22 & 0,36 & 0,19 & 0,01 & 0,10 & 0,23 & 0,36 & 0,18 & 0,01 \\
$2011-12$ & 0,09 & 0,28 & 0,40 & 0,34 & 0,05 & 0,08 & 0,20 & 0,34 & 0,35 & 0,05 & 0,06 & 0,21 & 0,32 & 0,29 & 0,05 \\
$2012-13$ & 0,05 & 0,15 & 0,25 & 0,27 & 0,05 & 0,07 & 0,20 & 0,29 & 0,32 & 0,04 & 0,06 & 0,19 & 0,29 & 0,30 & 0,05 \\
$2013-14$ & 0,08 & 0,16 & 0,25 & 0,34 & 0,07 & 0,11 & 0,29 & 0,38 & 0,41 & 0,09 & 0,09 & 0,26 & 0,34 & 0,39 & 0,08 \\
$2014-15$ & 0,04 & 0,10 & 0,26 & 0,15 & 0,07 & 0,04 & 0,11 & 0,36 & 0,13 & 0,06 & 0,04 & 0,11 & 0,32 & 0,13 & 0,07 \\
$2015-16$ & 0,04 & 0,11 & 0,20 & 0,09 & 0,08 & 0,05 & 0,19 & 0,38 & 0,15 & 0,08 & 0,06 & 0,18 & 0,34 & 0,14 & 0,09 \\
$2016-17$ & 0,04 & 0,10 & 0,23 & 0,11 & 0,07 & 0,06 & 0,20 & 0,49 & 0,22 & 0,13 & 0,06 & 0,19 & 0,44 & 0,19 & 0,13 \\
\hline
\end{tabular}

\subsection{Deeper Renovation Rates}

\subsubsection{3-step energy label renovation (RR3)}

The RR3 percentages are within a range (0.00-0.19\%) and even lower than RR2. For all sectors and before 2014, the highest RR3 are from (E to $\mathrm{B}$ ) and (F to $\mathrm{C}$ ). For the rental sectors and 2011-2013, (E to B) has higher percentages compared to ( $\mathrm{F}$ to $\mathrm{C}$ ). However, other types of renovations have very low percentages and almost no considerable change is identified $(0-0.08 \%)$.
Table 4. Three- Steps energy labels in different sectors ${ }^{3}$

\begin{tabular}{c|llll|llll|llll}
\hline \multicolumn{1}{c}{ RR3-O } & \multicolumn{1}{c}{ RR3-S } \\
\hline Labels & G-D & F-C & E-B & D-A & G-D & F-C & E-B & D-A & G-D & F-C & E-B & D-A \\
$2008-9$ & 0,05 & 0,04 & 0,04 & & 0,06 & 0,05 & 0,11 & 0,01 & 0,05 & 0,05 & 0,07 & \\
$2009-10$ & 0,04 & 0,05 & 0,05 & & 0,03 & 0,04 & 0,04 & & 0,04 & 0,04 & 0,04 & 0,00 \\
$2010-11$ & 0,08 & 0,17 & 0,18 & 0,03 & 0,05 & 0,12 & 0,12 & 0,02 & 0,07 & 0,12 & 0,13 & 0,02 \\
$2011-12$ & 0,07 & 0,17 & 0,17 & 0,06 & 0,05 & 0,12 & 0,16 & 0,08 & 0,05 & 0,13 & 0,13 & 0,05 \\
$2012-13$ & 0,04 & 0,07 & 0,09 & 0,05 & 0,04 & 0,10 & 0,14 & 0,07 & 0,04 & 0,08 & 0,14 & 0,06 \\
$2013-14$ & 0,04 & 0,11 & 0,14 & 0,06 & 0,07 & 0,14 & 0,19 & 0,08 & 0,07 & 0,12 & 0,18 & 0,07 \\
$2014-15$ & 0,05 & 0,14 & 0,04 & 0,05 & 0,04 & 0,16 & 0,07 & 0,06 & 0,05 & 0,17 & 0,06 & 0,06 \\
$2015-16$ & 0,05 & 0,09 & 0,02 & 0,04 & 0,06 & 0,15 & 0,04 & 0,05 & 0,06 & 0,15 & 0,04 & 0,05 \\
$2016-17$ & 0,04 & 0,10 & 0,03 & 0,04 & 0,06 & 0,20 & 0,05 & 0,07 & 0,07 & 0,19 & 0,06 & 0,05 \\
\hline
\end{tabular}

\subsubsection{4-step energy label renovation (RR4)}

For all sectors and before 2014, the highest percentages of RR4 are for the (F to B). After 2014, the RR4 from ( $G$ to C) has the highest percentages. The highest percentage is for the social housing sector, for the (F to B in year 2011-12), and equal to $0.13 \%$.

\begin{tabular}{l|lll|lll|lll} 
Table 5. Four-Steps energy labels in different sectors \\
\hline \multicolumn{1}{c}{ RR4-O } \\
\hline Labels & G-C & F-B & E-A & G-C & F-B & E-A & G-C & F-B & E-A \\
2008-9 & 0,04 & 0,02 & 0,02 & 0,02 & 0,02 & 0,01 & 0,03 & 0,02 & 0,01 \\
$2009-10$ & 0,02 & 0,03 & 0,00 & 0,01 & 0,01 & 0,01 & 0,01 & 0,01 & 0,00 \\
$2010-11$ & 0,05 & 0,08 & 0,03 & 0,03 & 0,07 & 0,01 & 0,04 & 0,07 & 0,01 \\
$2011-12$ & 0,06 & 0,12 & 0,05 & 0,07 & 0,13 & 0,04 & 0,07 & 0,12 & 0,03 \\
$2012-13$ & 0,02 & 0,07 & 0,04 & 0,04 & 0,09 & 0,05 & 0,03 & 0,09 & 0,04 \\
$2013-14$ & 0,03 & 0,08 & 0,04 & 0,04 & 0,12 & 0,06 & 0,05 & 0,10 & 0,05 \\
$2014-15$ & 0,06 & 0,02 & 0,03 & 0,06 & 0,03 & 0,05 & 0,06 & 0,03 & 0,04 \\
$2015-16$ & 0,04 & 0,00 & 0,03 & 0,07 & 0,02 & 0,05 & 0,07 & 0,02 & 0,05 \\
$2016-17$ & 0,05 & 0,01 & 0,03 & 0,07 & 0,01 & 0,04 & 0,09 & 0,01 & 0,05 \\
\hline
\end{tabular}

\subsubsection{5-step energy label renovation (RR5)}

In the owner-occupied sector, the percentages of RR5 are very minor compared to RR4 and it ranges between (0.006$0.046 \%$ ). The highest achievements are for the years 2010-11 and 2011-12 (Fig 11).

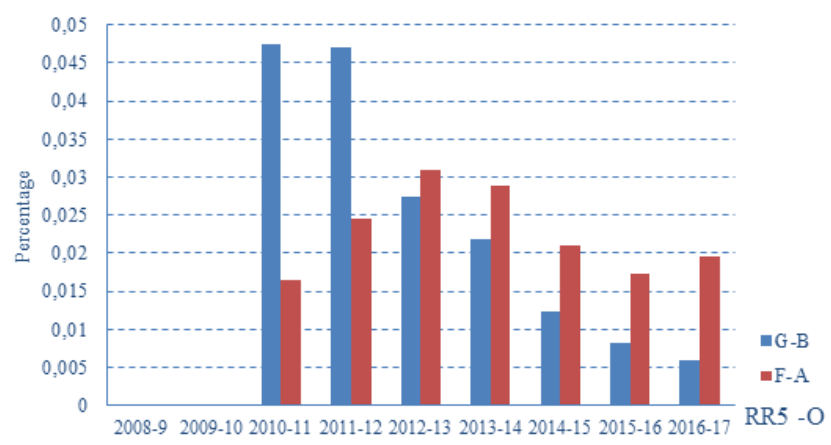

Fig 11. Major renovation rates (5-step) in the owner-occupied sector $^{4}$

For the rental sectors, the percentages of RR5 is also very small. The highest percentages are for the social housing sector with the range from (0.005-0.06\%). Between 20092012, the ( $\mathrm{G}$ to $\mathrm{B}$ ) has higher percentages. After 2012, (F to A) were higher (Fig 12 and Fig 13).

\footnotetext{
3 The empty cells are due to restriction of accessing to the data.

${ }^{4}$ The empty years are due to restriction of accessing to the data.
} 


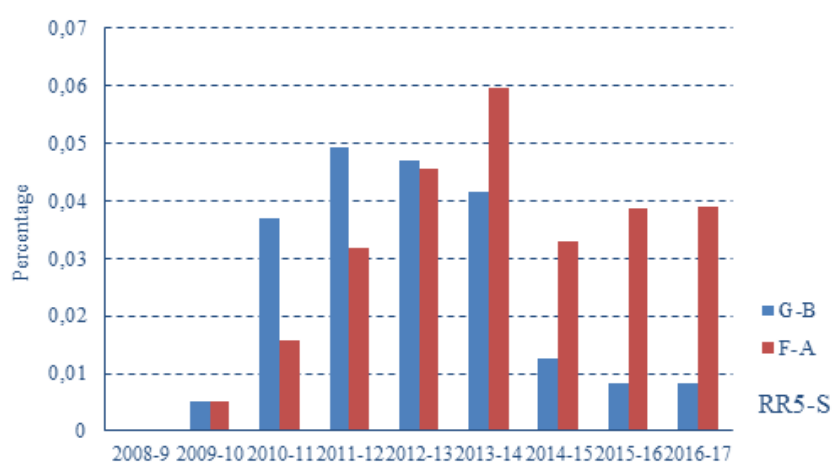

Fig 12. Major renovation rates (5-step) in the social housing

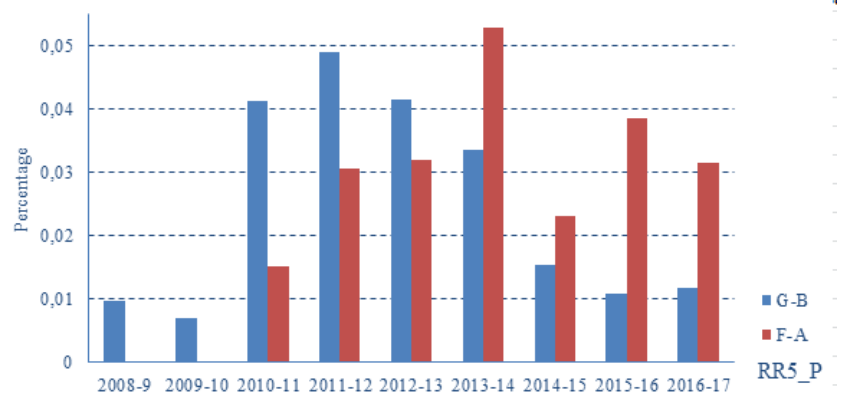

Fig 13. Major renovation rates (5-step) in the private rental sector

\section{Conclusions and Recommendations}

The main aim of this paper was to evaluate and compare the renovation rates in the owner-occupied and rental housing sectors. According to the results and the outcomes of this study:

- The differences of the renovation rates between the sectors are small and the social housing sector has a slightly higher renovation rate compared to the owner-occupied and private rental sectors. This is surprising because we expected that the number of renovations would be significantly higher for the social housing sector as they signed the previously mentioned covenant, there were more subsidies, and because they are more centrally organised - which could make it easier to conduct structural renovation plans on a larger scale. This result implies that even without covenant and fewer subsidies, homeowners renovate their house as frequent as social housing associations renovate their houses.

- By far the majority of the renovations are "small" renovations. With small renovations in this context we mean renovations that create an improvement of one to maximum two label steps defined by Filippidou et al (2017) ${ }^{2}$.

- When we looked at major renovations (at least 5 label steps improvement) we noticed that the percentage of dwellings that are renovated from an $F$ label house to an A label house is lower than for the other renovations.

- Contrary to what we might expect, due to different new energy saving targets, the renovation rate per year is not increasing
- Previous Dutch studies often focussed on the social housing sector because their data is more available. If the results of this research would be representative one could conclude that the previous studies concerning the energy efficiency state of the social housing stock are also representative for the total Dutch housing stock.

The current conclusions are only valid for the examined dataset. In order to generalize the results of this paper more research has to be done:

- The calculation method of the energy label has changed in 2014. This could imply that some buildings get a different energy label due to the updated calculation method and not due to an actual renovation. Therefore, the impact of the changed calculation method has to be studied.

- In the analysis we didn't consider that dwellings in the Netherlands are sometimes bought and renovated by investors and afterwards sold or rented out just to make profit. Because it is unclear how frequently this happens we don't know to which extent this influences the results. Further research should be conducted to investigate this phenomenon.

- It is unclear if the buildings in the database form a representative sample of the total housing stock in the Netherlands, also this should be further investigated.

- For the owner-occupied sector, since 2008 it is mandatory to provide a document that describes the energy performance of the house. But only since 2015 it has been mandatory to provide a definite energy label. Access to this information and data is difficult to be acquired.

To determine the effectiveness of the different renovations per sector a follow up research should be conducted including actual energy consumption/savings of the renovated buildings.

\section{References}

1. CBS. Higher CO2 emissions in Q1 2018. (2018). Available at: https://www.cbs.nl/engb/news/2018/20/higher-co2-emissions-in-q12018. (Accessed: 29th December 2018)

2. Filippidou, F., Nieboer, N. \& Visscher, H. Are we moving fast enough? The energy renovation rate of the Dutch non-profit housing using the national energy labelling database. Energy Policy 109, 488-498 (2017).

3. International Energy Agency (IEA). Energy labels for homes, 2007 - 2016 Compendium for the Living Environment. (2017). Available at: https://www.clo.nl/indicatoren/n10556energielabels-woningen. (Accessed: 29th December 2018) 
4. European Commission. Statistical Pocketbook 2018.

5. Sandberg, N. H. et al. Dynamic building stock modelling: Application to 11 European countries to support the energy efficiency and retrofit ambitions of the EU. Energy Build. 132, 26-38 (2016).

6. Stadler, M., Kranzl, L., Huber, C., Haas, R. \& Tsioliaridou, E. Policy strategies and paths to promote sustainable energy systems - The dynamic Invert simulation tool. Energy Policy 35, 597-608 (2007).

7. BPIE. Europe's Buildings Uneder The Microscope. (2011). doi:ISBN:

9789491143014

8. Parliament, E. COMMISSION DELEGATED REGULATION (EU) No 244/2012. (2012).

9. Boermans, T. et al. Public Consultation on the Evaluation of Directive 2010/31/EU. Final synthesis report. (2015).

10. Dixton, T., Eames, M., Hunt, M. \& Lannon, S. Urban Retrofitting for Sustainability. Urban Retrofitting for Sustainability: Mapping the Transition to 2050 (2014). doi:10.4324/9781315850184

11. European Comission. Buildings - European Commission. 4-7 (2016). Available at: https://ec.europa.eu/energy/en/topics/energyefficiency/buildings. (Accessed: 23rd October 2017)

12. Filippidou, F. Energy perfrmance progress of the Dutch non-profit housing stock: a longitudinal assessment. (2018).

13. Artola, I., Rademaekers, K., Williams, R. \& Yearwood, J. Boosting Building Renovation: What potential and value for Europe? (2016). doi: $10.2861 / 331360$

14. Filippidou, F., Nieboer, N. \& Visscher, H. Effectiveness of energy renovations: a reassessment based on actual consumption savings. Energy Effic. 1-17 (2018).

doi:10.1007/s12053-018-9634-8

15. van den Brom, P., Meijer, A. \& Visscher, H. Actual energy saving effects of thermal renovations in dwellings - longitudinal data analysis including building and occupant characteristics. Energy Build. (2018). doi:10.1016/j.enbuild.2018.10.025

16. Eurostat. Consumption in the EU above the energy efficiency target. 4-7 (2018).

17. Statistics Netherlands (CBS). CBS Open data StatLine. (2018). Available at: https://opendata.cbs.nl/statline/portal.html? la= nl\&_catalog $=$ CBS. (Accessed: 29th December 2018)

18. Parliament, E. EPBD recast. (2010).
19. European Parliament. Revised Energy Efficiency Directive. DG Energy portal (2017).

20. EU, E. U. Directive 2018/844/EU Energy performance of buildings. Off. J. Eur. Union 2018, 75-91 (2018).

21. Boot, P. A. Energy efficiency obligations in the Netherlands - A role for white certificates? (2009). 